\title{
Ehlers-Danlos Syndrome Type Vl: A Case Report
}

\author{
Ehler-Danlos Sendromu Tip VI: Olgu Sunumu
}

\author{
Mehmet CANPOLAT ${ }^{1}$, Nagihan ERDOG ŞAHIN² , Fatih KARDAŞ ${ }^{3}$, Mehmet KÖSE ${ }^{4}$, Hakan GÜMÜŞ' ${ }^{1}$, \\ Hüseyin PER ${ }^{1}$, Sefer KUMANDAȘ ${ }^{1}$
}

\begin{abstract}
${ }^{1}$ Erciyes University, Faculty of Medicine, Department of Child Health and Diseases, Pediatric Neurology, Kayseri, Turkey ${ }^{2}$ Erciyes University, Faculty of Medicine, Department of Child Health and Diseases, Kayseri, Turkey

${ }^{3}$ Erciyes University, Faculty of Medicine, Department of Child Health and Diseases, Child Nutrition and Metabolism, Kayseri, Turkey

${ }^{4}$ Erciyes University, Faculty of Medicine, Department of Child Health and Diseases, Pediatric Pulmonology, Kayseri, Turkey
\end{abstract}

\begin{abstract}
The kyphoscoliotic type of Ehlers-Danlos syndrome (EDS), type VI, is a rare autosomal recessive connective tissue disorder characterized at birth by severe muscular hypotonia, kyphoscoliosis which is progressive and severe, marked joint hypermobility and luxations and severe skin hyperelasticity. It is characterized by a deficiency of collagen lysyl hydroxylase due to mutations in procollagen-lysine, 2-oxoglutarate 5-dioxygenase 1 (PLOD1 or lysyl hydroxylase 1). The ratio of urinary total LP to HP in patients with EDS VI is high as compared with normal controls, and is diagnostic for this disease. Herein, we describe a 7-year-old female with the kyphoscoliotic type of Ehlers-Danlos syndrome (EDS VI) who was admitted with complaints of curvature of the spine.
\end{abstract}

Key Words: Child, Ehlers-Danlos syndrome, Hypotonia, Kyphoscoliosis

\section{ÖZET}

Kifoskolyotik tip Ehlers-Danlos sendromu (EDS), tip VI, doğumdan itibaren varolan ciddi muskuler hipotoni, progresif ve ciddi kifoskolyoz, belirgin eklem hipermobilitesi ve luksasyon ve ciddi deri hiperelastikiyeti ile karakterize nadir otozomal resesif bir bağ doku hastalığıdır. Prokolajen-lizin-2-oksoglutarat 5-dioksijenaz 1(PLOD1 veya lizil hidroksilaz 1) gen mutasyonu sonucu bu hastalarda kolajen lizil hidroksilaz enzim eksikliği ile görülmektedir. Normal sağlıklı kontroller ile karşılaştırıldıklarında, idrarda artmış total lizil pridinoline/hidroksi pridinoline oranları yüksektir ve bu durum hastalık için tanı koydurucudur. Bu vakada omurga eğriliği şikayeti ile başvuran ve kisosfolyotik tip Ehlers-Danlos sendromu tanısı alan 7 yaşında kız sunuldu.

Anahtar Sözcükler: Çocuk, Ehlers-Danlos sendromu, Hipotoni, Kifoskolyoz

\section{INTRODUCTION}

The kyphoscoliotic type of Ehlers-Danlos syndrome (EDS), type $\mathrm{VI}$ (MIM 225400), is a rare autosomal recessive connective tissue disorder characterized at birth by severe muscular hypotonia often requiring invasive neuromuscular work-up, kyphoscoliosis that is progressive and severe, marked joint hypermobility and luxations, and severe skin hyperelasticity (1). Marfanoid habitus, fragile eyeballs, osteopenia, and occasionally vascular fragility can also be seen and these are classified as minor diagnostic criteria for the disease (2-4). Biochemically, it is characterized by a deficiency of collagen lysyl hydroxylase (EC 1.14.11.4) due to mutations in procollagen-lysine, 2-oxoglutarate 5-dioxygenase 1 (PLOD1 or lysyl hydroxylase 1) (5).

The ratio of urinary total $L P$ to HP in patients with EDS VI is high as compared with normal controls, and is diagnostic for this disease $(2,5)$. Additionally, assay of lysyl hydroxylase enzyme activity in skin fibroblasts is diagnostic. Molecular genetic testing of PLOD1, the only gene known to be associated with EDS, kyphoscoliotic form, is available (4). Herein, we describe a 7-year-old female with the kyphoscoliotic type of Ehlers-Danlos syndrome (EDS VI) who was admitted with complaints of curvature of the spine. 


\section{CASE REPORT}

A 7 year-old female was admitted to hospital with complaints of curvature of the spine. She was the first child of consanguineous parents of Turkish origin. There was no history of similar illness in the family. From her medical history we learnt that she had been born by caesarean section because of breech birth in the mother's first pregnancy, was born at full term, with a weight of 3200 grams but her length and head circumference were not recorded. She had been admitted to hospital with inability to walk, hypotonia and muscular weakness at one year old. Genetic testing had been conducted considering an initial diagnosis of spinal muscular dystrophy, but the test results were normal. She had been operated on for developmental hip dysplasia at two and half years old and had walked at four years old. Kyphoscoliosis which developed in the first year of life was worsened. This had significantly increased in the last two years. On her physical examinations, her skin was soft and hyperelastic, and the cicatricial skin normal. Creatine phosphokinase, echocardiographic evaluation and nerve conduction velocity were normal. Her IQ value was 107 points (according to the Stanford Binet test). Ophthalmologic examination was normal. There was a curvature of the spine that was pointing to the right. Kyphoscoliosis was determined at thoracolumbar X-ray and rotoscoliosis was determined at thoracospinal MRI (Figure1). In her skin biopsy, distinct collagen fibers and edema were observed. Urine samples for urinary pyridinolines were analyzed by automated HPLC assay. The ratio of urinary total pyridinolines, that is lysyl pyridinoline (443.00 nM/mM Cr)/hydroxylysyl pyridinoline (102.00 nM/mM $\mathrm{Cr})(\mathrm{LP} / \mathrm{HP})$ was 4.34 (normal range: $0.19 \pm 0.02)$. The patient was diagnosed with Type VI EDS by clinical and laboratory findings.

\section{DISCUSSION}

Ehlers-Danlos syndrome(EDS) is a group of generalized disorders characterized by abnormalities of the connective tissue leading to fragility of the skin and blood vessels, hyperextensibility of the skin, and joint hypermobility (6). The kyphoscoliotic-type of EDS, type VI (MIM 225400), is a rare autosomal recessive connective tissue disorder. The kyphoscoliotic-type affects the musculoskeletal system leading to hypotonia, kyphoscoliosis and joint hyperextensibility in the first years of life $(1,5)$. The exact prevalence of EDS $\mathrm{VI}$ is unknown but presumed to be world-wide approximately 1:100,000 live births (4). It is very rare in Turkey where consanguineous marriages are frequent. To the best of our knowledge fewer than 5 cases have been reported in the literature. Muscular weakness and hypotonia were present in our case and she was the child of consanguineous parents.

Kyphoscoliosis is a hallmark of the disease and is often severe and progressive. In cases with progressive kyphoscoliosis,

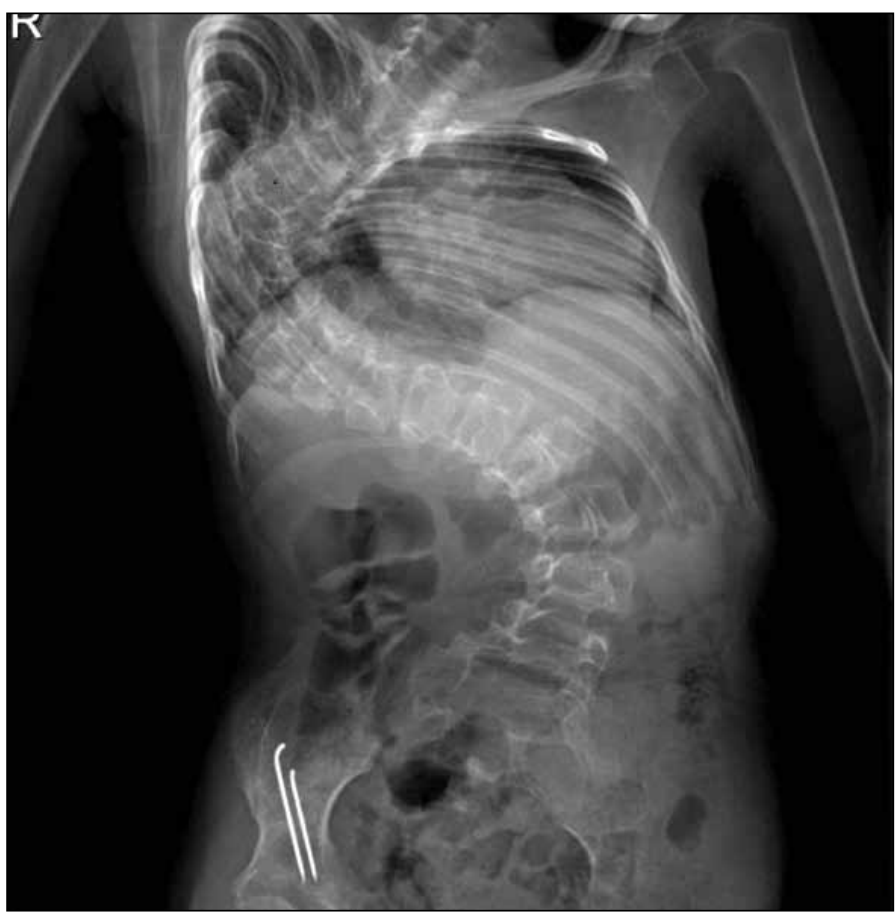

Figure 1: Kyphoscoliosis at thoracolumbar X-ray.

thoracic cage deformity and hypotonia lead to a decrease in pulmonary function and favor recurrent episodes of pneumonia and early death (7). Management of kyphoscoliosis by an orthopedic surgeon, including surgery as needed and physical therapy to strengthen large muscle groups can be given (4).

The kyphoscoliotic form of EDS is caused by deficient activity of the enzyme lysyl hydroxylase-1. Therefore, lysyl hydroxylase deficiency, which is an important enzyme in collagen types III, IV, and VI biosynthesis, leads to clinical symptoms of hypermobile joints, soft hyperextensible skin with bad scarring and easy bruising, and kyphoscoliosis, as seen in patients with EDS type VI (8). EDS kyphoscoliotic form has some overlapping clinical features with other forms of EDS, especially EDS classic type and EDS vascular type (4). Abnormal wound healing and joint laxity are present in many EDS types (4). Even though all types of EDS involve a relatively high risk for scoliosis compared to the general population, scoliosis in EDS kyphoscoliotic form is usually more severe and of earlier onset than that seen in other EDS types (4). The clinical diagnosis of EDS VI is confirmed at the biochemical level by a deficiency of the important collagen modifying enzyme. The ratio of urinary total LP to HP in patients with EDS VI is high as compared with normal controls and is diagnostic for this disease $(2,5)$. Assessment of the ratio of urinary total LP to HP is an easy, quick and inexpensive method to determine the differential diagnosis of EDS type $\mathrm{VI}$ and other neuromuscular disorders. Furthermore, to assay the enzyme activity in skin fibroplasts and test genetic mutations for PLOD1 are other ways to determine EDS type VI. The most common PLOD1 mutation is a duplication of exons 10-16, accounting for about $25 \%$ of all reported cases $(5,8)$. Inheritance is 
autosomal recessive. In the case presented here, the ratio of urinary total pyridinolines, lysyl pyridinoline/hydroxylysyl pyridinoline (LP/HP) was 4.34. Due to lack of technical facilities and financial problems, molecular genetic testing of PLOD1, or lysyl hydroxylase enzyme activity assay was not performed. The patient was diagnosed with Type VI EDS by clinical and laboratory findings.

Familial joint hypermobility syndrome (JHS) and other syndromes in which joint hypermobility is found share hypermobility of the joints with classic EDS, but the absence of skin hyperextensibility and atrophic scarring excludes the diagnosis of classic EDS (3). Diseases that have generalized joint laxity as a clinical feature are included in the differential diagnosis of JHS. Each of these disorders, with the exception of the hypermobile type of EhlersDanlos syndrome, has one or more characteristic features that serve to distinguish it from JHS. Although there is a variable phenotypic expression of Marfan syndrome, there are certain features involving the skeletal, cardiovascular, and ocular systems that are considered major manifestations of the disease. Summarized briefly, they include reduced upper to lower body segment ratio, arm span exceeding height, arachnodactyly of the fingers and toes, scoliosis, kyphosis, dilation of the proximal aorta, aortic dissection, ectopia lentis, or dural ectasia. Marfan syndrome is a clinical diagnosis based on family history and the observation of characteristic findings in multiple organ systems. Diagnostic criteria have been established. Molecular genetic testing of the FBN1 gene is possible. Inheritance is autosomal dominant (3). If a diagnosis of Ehlers-Danlos syndrome other than the hypermobile type is suspected, diagnosis may be made by molecular genetic testing or by analysis of collagen obtained from cultured dermal fibroblasts (3, 4, 7-13). In the case presented here, skin biopsy, distinct collagen fibers and edema were observed.

Because of severe muscle hypotonia and delayed motor development, children with EDS VIA are initially often suspected to have a primary neuromuscular disease. However, neuromuscular workup in the neonatal period mostly yields normal results (11). Several congenital myopathies present with poor muscle tone and increased range of motion of the small and large joints. Joint laxity can be difficult to differentiate from muscular hypotonia, especially in infants and children (4). Infants affected with EDS VI present with moderate to severe generalized muscle hypotonia, and with skeletal findings such as kyphoscoliosis and joint hyperextensibility that are common to neuromuscular disorders such as Bethlem myopathy and Ullrich muscular dystrophy (5). In most patients documented in the literature, hypotonia in conjunction with the inability to stabilize the joints, due to laxity of the connective tissue, leads to a delay in gross motor development in the first years of life $(5,7,13)$. Indeed, infants affected with EDS VI are usually suspected of having congenital muscular dystrophies, congenital myopathies and lower motor neuron diseases, because of the muscular hypotonia and delay in gross motor development, and especially when deformities of the feet and joint dislocations coexist (5). This explains why an extensive, often invasive neuromuscular work-up is usually performed with normal results $(5,13)$. In EDS kyphoscoliotic form, in which both hypotonia and joint laxity are present, the increased range of motion is often striking (4). Excessive laxity of the skin and atrophic (cigarette paper-like) skin texture may help distinguish EDS kyphoscoliotic form from congenital myopathies, such as X-linked myotubular myopathy (4). In all affected individuals, serum creatine kinase levels were normal or only slightly elevated (range 60-300 IU/I) (11). Unlike spinal muscular atrophy, EDS kyphoscoliotic form is characterized by normal deep tendon reflexes (4). In the case presented here, neuromuscular workup, deep tendon reflexes and muscle enzymes were normal.

In addition, many syndromic and metabolic disorders include early-onset hypotonia. In these disorders, biochemical analysis reveals normal ratios of urinary pyridinolines and lysyl hydroxylase enzyme activity (4).

In conclusion, physicians should consider EDS type VI as one of the differential diagnoses for hypotonia and muscular weakness in infants. The presence of positive findings such as scoliosis, hypermobility and hyperelastic skin can be associated with EDS type VI. Analysis of urinary pyridinolines should be performed next to confirm the diagnosis. Urine analysis is a specific, sensitive and inexpensive method to rule in or out EDS type VI.

\section{REFERENCES}

1. Gok E, Goksel OS, Alpagut U, Dayioglu E. Spontaneous brachial pseudo-aneurysm in a 12-year-old with kyphoscoliosis-type EhlersDanlos Syndrome. Eur J Vasc Endovasc Surg 2012;44:482-4.

2. Steinmann B, Eyre DR, Shao P. Urinary pyridinoline cross-links in Ehlers-Danlos syndrome type VI. Am J Hum Genet 1995;57: 1505-8.

3. Malfait F, Wenstrup RJ, De Paepe A. Clinical and genetic aspects of Ehlers-Danlos syndrome, classic type. Genet Med 2010;12:597605.

4. Yeowell HN, Steinmann B. Ehlers-Danlos Syndrome, Kyphoscoliotic Form. 2000 Feb 02 [updated 2013 Jan 24]. In: Pagon RA, Bird TD, Dolan CR, Stephens K, Adam MP (eds). GeneReviews ${ }^{\circledR}$ [Internet]. Seattle (WA): University of Washington, Seattle; 1993-2014.

5. Yiş U, Dirik E, Chambaz C, Steinmann B, Giunta C. Differential diagnosis of muscular hypotonia in infants: The kyphoscoliotic type of Ehlers-Danlos syndrome (EDS VI). Neuromuscul Disord 2008;18:210-4.

6. Karrer S, Landthaler M, Schmalz G. Ehlers-Danlos type VIII. Review of the literature. Clin Oral Investig 2000;4:66-9.

7. Steinmann B, Royce PM, Superti-Furga A. The Ehlers-Danlos syndrome. In: Royce PMB, Steinmann B (eds), Connective Tissue and its Heritable Disorders 2nd ed. New York: Wiley, 2002: 431-523.

8. Yeowell HN, Walker LC. Mutations in the lysyl hydroxylase 1 gene that result in enzyme deficiency and the clinical phenotype of Ehlers-Danlos syndrome type VI. Mol Genet Metab 2000;71: 212-24. 
9. Malfait F, Syx D, Vlummens P, Symoens S, Nampoothiri S, Hermanns-Lê $T$, et al. Musculocontractural Ehlers-Danlos syndrome (former EDS type VIB) and adducted thumb clubfoot syndrome (ATCS) represent a single clinical entity caused by mutations in the dermatan-4-sulfotransferase 1 encoding CHST14 gene. Hum Mutat 2010;31:1233-9.

10. Giunta C, Elçioglu NH, Albrecht B, Eich G, Chambaz C, Janecke $A R$, et al. Spondylocheiro dysplastic form of the Ehlers-Danlos syndrome - an autosomal-recessive entity caused by mutations in the zinc transporter gene SLC39A13. Am J Hum Genet 2008;82:1290-1305.

11. Baumann M, Giunta C, Krabichler B, Rüschendorf F, Zoppi N, Colombi M, et al. Mutations in FKBP14 cause a variant of EhlersDanlos syndrome with progressive kyphoscoliosis, myopathy and hearing loss. Am J Hum Genet 2012;90:201-16.
12. Al-Hussain H, Zeisberger SM, Huber PR, Giunta C, Steinmann B. Brittle cornea syndrome and its delineation from the kyphoscoliotic type of Ehlers-Danlos syndrome (EDS VI): Report on 23 patients and review of the literature. Am J Med Genet A 2004;124A:28-34.

13. Giunta C, Randolph A, Al-Gazali LI, Brunner HG, Kraenzlin ME, Steinmann B. Nevo syndrome is allelic to the kyphoscoliotic type of the Ehlers-Danlos syndrome (EDS VIA). Am J Med Genet A 2005;133:158-64. 